enrolled patients simultaneously by the use of Reverse Transcription-Multiplex PCR technique (RT-m PCR). Viral pneumonia was detected in one third of enrolled patients (8/24), with predominance of respiratory syncytial virus A (4/8), followed by Influenza A virus $(3 / 8)$ and Influenza B virus (1/8) while no cases of respiratory syncytial virus $B$ were detected. The same results were identified in both blood and respiratory specimens.

Conclusion Reverse Transcription-Multiplex PCR technique Multiplex has a significant advantage in that it permits simultaneous amplification of several viruses in a single reaction making this well suited for use in epidemiological studies and to improve etiologydirected clinical management of viral pneumonia.

\section{CLINICAL FEATURES OF MYCOPLASMAL PNEUMONIA AT EARLY AGE CHILDREN}

doi:10.1136/archdischild-2012-302724.0914

H Alimova, G Nuralieva, M Alibekova. Republican Research Centre of Emergency Medicine, Tashkent, Uzbekistan

Background and Aims In recent years the problem of mycoplasmal pneumonia, especially in early age children attracted the attention of pediatricians around the world. Purpose - to study the peculiarities of clinical course of mycoplasmal pneumonia in early age children.

Methods From 2009 to 2011 among children with pneumonia analyzed for the presence of mycoplasmal pneumoniae. The study involve 450 children aged 5 months to 3 years. Antibodies to Mycoplasma pneumoniae were detected by ELISA in 60 children. Raising antibodies indicated more than 4 times. Conducted clinical observations, X-ray methods, the method of ELISA for the detection of IgM antibodies to Mycoplasma pneumoniae, DNA display M. pneumoniae in sputum by PCR.

Results Mycoplasmal pneumonia began sharply at $80 \%$ of children with high fever, cough was dry and unproductive. Outpatient treatment starting antibiotics penicillin group did not give the effect. Pyrexia over $38^{\circ} \mathrm{C}$ was observed in $95 \%$ of children.

On radiographic studies, the bilateral homogeneous lobular infiltration revealed in the lungs at the majority of children (75\%). Segmental nature of the infiltrative changes detected in $5 \%$ right-sided focal character pneumonic process occurred in $20 \%$, left-side lung had $9.5 \%$ of children. In the analysis of peripheral blood revealed anemia in $25 \%$ of children, moderate leukocytosis in $89 \%$, marked lymphocytosis (95\%) and accelerated erythrocyte sedimentation rate $(89 \%)$.

Conclusion For early age children with mycoplasmal pneumonia is characterized by severe intoxication, prolonged dry cough. On the radiograph indicated bilateral focal mainly infiltration. In the hemogram - a moderate leukocytosis, lymphocytosis, ESR acceleration.

\section{FURAZOLIDONE AS AN ANTIBIOTIC FOR CHILDHOOD GASTROENTERITIS AND ITS COMPARISON WITH WHO GUIDELINE: IS IT USED STILL?}

doi:10.1136/archdischild-2012-302724.0915

'F Fayyaz Jahani, 'E Ahmadnezhad, 'M Karramyyar. 'Urmia University of Medical Sciences, Urmia; ${ }^{2}$ Tehran University of Medical Sciences, Tehran, Iran

Background Furazolidon is an anti-parasitic and anti-bacterial drug that used specifically for Giardia as a second-line choice. Some complications was reported that in $10 \%$ of children complication occur with diarrhea-vomiting, in children with lack of G6PD, and in children less than 1 years old this drug is not prescribed and is forbidden. This study was conducted to compare of the prescriptions of Furazolidone for treatment of diarrhea in children with the prevalence of Giardiasis.
Methods This is a cross-sectional study was done in North-west of Iran. As first step, we obtained the prevalence of acute gastroenteritis in this area for 2009 then all of related prescription that had inclusion criteria were evaluated in 2010. Related prescriptions adjusted by Furazlidone using frequencies.

Results In the primary study we found out that the total usage of drags in first nine month of 2009 as below: 840425 Cotrimoxasole, 619044 Metronidazol, 174817 Furazolidone. There are total 1231 antibiotic syrup prescribed by physicians and pediatritions that 174 (14.1\%) of them include the furazolidone. From this amount, 18.9\% prescribed for children less than 1 years old, $23.6 \%$ prescribed for children $1-2$ years old, $14.2 \%$ for $2-3$ years old, $23.4 \%$ for $3-5$ years old and $19.1 \%$ prescribed for children $5-7$ years old. Conclusion: According to Giradia' prevalence (3.5\%) and Furazolidone prescribing (174) for acute diarrhea, we can conclude that $75 \%$ of usage is more than prevalence of it's indication for acute diarrhea. Further studies and effective training programs are urgently needed to reverse current irrational treatment practices.

\section{CLINICAL PARACLINICAL CHARACTERISTIC OF MEASLES IN THE CHILDREN IN THE ENDEMIC REGION}

doi:10.1136/archdischild-2012-302724.0916

OM Horlenko, MA Polyak. Pediatrics with Infectious Diseases, Uzhgorod National University, Medical Faculty, Uzhgorod, Ukraine

Backgraund and aims In this article we showed features of duration Measles in children from endemic region.

Methods We investiganed 69 children with Measles in age from 3 to 15 months which used treatment in Uzhgorod Regional Clinical Infectious Hospital during 2012 years. All children were conducted by complex anamnestic and clinical paraclinical inspection.

Results 61 children (88.4\%) had positive measles Ig M. Nobody of inspected in the past have't Measles and had routine measles vaccination. The first sign of measles were a high fever ( 55 childs, $79.7 \%$ ). A runny nose, a cough, red and watery eyes, and small white spots inside the cheeks developed in the initial stage. The first elements of rash appeared in patients were on face, which then spread on the neck, overhead part of breast, and on the second days were appeared on a trunk, pands, hands, on the third days-on legs. Rash in the prevalence cases was maculopapular, but in 19 childs, $27.5 \%$ was generaly slight; in 4 childs, $5.7 \%$ patients-slightly hemorragic. Duration of rash was amount 4.7 days. Local pneumonia was confirmed in 7 patients $(10.1 \%)$, in $5(7.2 \%)$ - bronchiolitis, $5(7.2 \%)$ - had obstructive bronchitis. Biochemistry investigation of blood serum identificated decline of Albumens-2 (2.8\%), Creatinine-22 (31.8\%), Proteinum-23(33.3\%), General Bilirubinum-2(2.8\%), ALT-3(4.3\%), AST-31(44.9\%), Alkaline Phosphatase-12(17.3\%).

Conclusions Routine measles vaccination for children, combined with mass immunization campaigns in countries with high case and death rates, are key public health strategies to reduce global measles complication.

\section{ROTAVIRUS DIARRHOEA IN THE CHILDREN FROM ENDEMIC REGION}

doi:10.1136/archdischild-2012-302724.0917

OM Horlenko, NM Stoika, MA Polyak. Pediatrics and Infectious Diseases, Uzhgorod National University, Medical Faculty, Uzhgorod, Ukraine

Backgraund and aims: In Ukraine frequency of Rotavirus infection (RI) contain $35-75 \%$ of all cases of acute intestinal infections. Methods We investigated 90 children with rotavirus infection (age 1-5years), which used treatment in the infectious hospital during 2011 year. The group of children with RI distributed by gender signs: boys -47 (52.2\%), girls - $43(47.8 \%)$. And by age: $1-3$ years $-60(66.6 \%), 3-4$ years - 20 children $(22.2 \%)$, after 4 years - 10 children $11.1 \%$ ). 